\title{
First Polish case of CSF1R-related leukoencephalopathy
}

\author{
Zbigniew K. Wszolek \\ Department of Neurology, Mayo Clinic Florida, Jacksonville, Florida, United States
}

(Neurol Neurochir Pol 2021; 55 (3): 239-240)

In this issue of the Polish Journal of Neurology and Neurosurgery, Żur-Wyrozumska, et al. describes the very first genetically proven case of CSF1R-related leukoencephalopathy in Poland [1]. CSF1R-related leukoencephalopathy (due to mutations in CSF1R gene [2]) has been reported in multiple countries around the world (reviewed in Konno, et al. [3]); however, despite its worldwide occurrence, CSF1R-related leukoencephalopathy is still an underdiagnosed condition [4].

There are three primary reasons for this diagnostic difficulty. The disease was first recognized by Van Bogaert and Nyssen back in 1936 [5] as a subset of orthochromatic leukodystrophies. They identified it as a pigmentary orthochromatic leukodystrophy (POLD). However, until the discovery of causative CSF1R gene mutations in 2011 [2], only a handful of sporadic and familiar POLD cases were published (reviewed in Marotti, et al. [6]). To diagnose it with certainty, either brain biopsy or autopsy had to be done.

The second reason relates to a nomenclature confusion leading to labeling many cases of POLD as hereditary diffuse leukoencephalopathy with spheroids (HDLS). For example, in our own first publication on this subject from 2006, we erroneously named a POLD family as an HDLS family [7]. HDLS was first describe by Axelsson et al in 1984 [8] in a Swedish family with clinical and pathologic similarities to POLD families. Recently, this family was found to carry mutations in AARS2 gene [9]. Even before this genetic discovery, we found that families mislabeled as HDLS were indeed POLD families
[10]. Fortunately, these nomenclature difficulties stemming from similarities in clinical and pathologic presentations have been solved by advances in genetic technology. The nomenclature introduced by Konno et al. [3] simplifies it, and now we identify these two separate conditions as CSF1R-related leukoencephalopathy, formerly POLD families, and AARS2-related leukoencephalopathy, formerly HDLS families (Tab. 1). Unfortunately, there are also published and unpublished cases/ /families suspected for CSF1R-related leukoencephalopathy or AARS2-related leukoencephalopathy with negative genetic testing for both CSF1R and AARS2 gene mutations [11, and personal observation]. Thus, the concept of adult-onset leukoencephalopathy with axonal spheroids and pigmented glia (ALSP), initially introduced by Marotti et al. [6] and further popularized by Wider et al. [11], is still quite useful. Konno et al. [3] make this distinction even more specific by introducing the term, CSF1R/AARS2-negative ALSP. It is very likely that there are other so far unidentified genes in which mutations are responsible for clinical and pathologic phenotypes currently indistinguishable from those seen in CSF1R-related leukoencephalopathy and AARS2-related leukoencephalopathy.

The third and most important reason is that clinical features of CSF1R-related leukoencephalopathy are very broad, encompassing headaches, seizures, spasticity, rigidity, tremors, psychiatric features, dementia, among others, thus leading to misdiagnosis or delayed diagnosis. Fortunately, a much wider availability of clinical genetic testing at this juncture makes

Table 1. Current and previously used nomenclature

Current nomenclature

CSFIR-related leukoencephalopathy

AARS2-related leukoencephalopathy

CSF1R/ANRS2-negative ALSP
Previously used nomenclature

POLD cases/families

Previously mislabeled HDLS cases/families

HDLS cases/families

Genetically negative for CSF1R/AARS2 mutation cases/families

CSF1R-related leukoencephalopathy - colony stimulating factor 1 receptor-related leukoencephalopathy; POLD — pigmented orthochromatic leukodystrophy; HDLS - hereditary diffuse leukoencephalopathy with axonal spheroids; AARS2-related leukoencephalopathy — alanyl tRNA synthetase-related leukoencephalopathy; ALSP — adult-onset leukoencephalopathy with axonal spheroids and pigmented glia

Address for correspondence: Zbigniew K. Wszolek, M.D., Department of Neurology, Mayo Clinic Florida, 4500 San Pablo Road, Jacksonville, Florida 32224, USA, e-mail: wszolek.zbigniew@mayo.edu 
the diagnosis easier and faster as demonstrated in the case presented by Żur-Wyrozumska et al. [1]. I congratulate Żur-Wyrozumska et al. for their diagnostic success and for bringing this case to the attention of the readership of the Polish Journal of Neurology and Neurosurgery. It is very likely that more cases of this disease will be identified in Poland.

At the present time, CSF1R-related leukoencephalopathy is an incurable disease. However, a better understanding of the pathophysiology and molecular biology of this illness makes development of a halting progression therapy a possibility [4]. In fact, hematopoietic stem cell transplantation has already been used to treat several patients (briefly discussed in Tipton, et al. [12]).

\section{References}

1. Żur-Wyrozumska K, Kaczmarska P, Mensah-Glanowska P. Adult-onset leukoencephalopathy with axonal spheroids and pigmented glia associated with an A792D mutation in the CSF1R gene in a Polish patient. Neurol Neurochir Pol. 2021 [Epub ahead of print], doi: 10.5603/ PJNNS.a2021.0012, indexed in Pubmed: 33528831.

2. Rademakers R, Baker M, Nicholson AM, et al. Mutations in the colony stimulating factor 1 receptor (CSF1R) gene cause hereditary diffuse leukoencephalopathy with spheroids. Nat Genet. 2011; 44(2): 200-205, doi: 10.1038/ng.1027, indexed in Pubmed: 22197934.

3. Konno T, Kasanuki K, Ikeuchi T, et al. CSF1R-related leukoencephalopathy: A major player in primary microgliopathies. Neurology. 2018; 91(24): 1092-1104, doi: 10.1212/WNL.0000000000006642, indexed in Pubmed: 30429277.

4. Kempthorne L, Yoon H, Madore C, et al. Loss of homeostatic microglial phenotype in CSF1R-related Leukoencephalopathy. Acta Neuropathol
Commun. 2020; 8(1): 72, doi: 10.1186/s40478-020-00947-0, indexed in Pubmed: 32430064.

5. Van Bo, Nyssen R. Le type tardif de la leukodystrophie progressive familiale. Rev Neurol. 1936; 65: 21-45.

6. Marotti JD, Tobias S, Fratkin JD, et al. Adult onset leukodystrophy with neuroaxonal spheroids and pigmented glia: report of a family, historical perspective, and review of the literature. Acta Neuropathol. 2004; 107(6): 481-488, doi: 10.1007/s00401-004-0847-x, indexed in Pubmed: 15067553.

7. Baba Y, Ghetti B, Baker MC, et al. Hereditary diffuse leukoencephalopathy with spheroids: clinical, pathologic and genetic studies of a new kindred. Acta Neuropathol. 2006; 111(4): 300-311, doi: 10.1007/ s00401-006-0046-z, indexed in Pubmed: 16523341.

8. Axelsson R, Röyttä M, Sourander P, et al. Hereditary diffuse leucoencephalopathy with spheroids. Acta Psychiatr Scand Suppl. 1984; 314: 1-65, indexed in Pubmed: 6595937.

9. Sundal C, Carmona S, Yhr M, et al. An AARS variant as the likely cause of Swedish type hereditary diffuse leukoencephalopathy with spheroids. Acta Neuropathol Commun. 2019; 7(1): 188, doi: 10.1186/ s40478-019-0843-y, indexed in Pubmed: 31775912.

10. Nicholson AM, Baker MC, Finch NA, et al. CSF1R mutations link POLD and HDLS as a single disease entity. Neurology. 2013; 80(11): 1033-1040, doi: 10.1212/WNL.0b013e31828726a7, indexed in Pubmed: 23408870.

11. Wider C, Van Gerpen JA, DeArmond S, et al. Leukoencephalopathy with spheroids (HDLS) and pigmentary leukodystrophy (POLD): a single entity? Neurology. 2009; 72(22): 1953-1959, doi: 10.1212/ WNL.0b013e3181a826c0, indexed in Pubmed: 19487654.

12. Tipton PW, Stanley ER, Chitu V, et al. Is Pre-Symptomatic Immunosuppression Protective in CSF1R-Related Leukoencephalopathy? Mov Disord. 2021 [Epub ahead of print], doi: 10.1002/mds.28515, indexed in Pubmed: 33590562. 